NASA Technical Memorandum 87211

\title{
Development and Application of Dynamic Simulations of a Subsonic Wind Tunnel
}

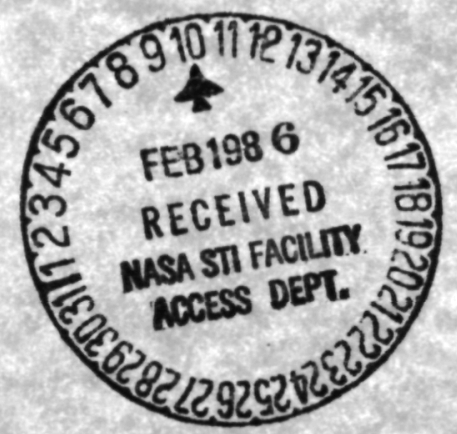

John R. Szuch, Gary L. Cole, Robert C. Seidel, and Dale J. Arpasi

Lewis Research Center

Cleveland, Ohio

$$
\begin{aligned}
& \text { (NASA-TM-87211) DEVELOPMENT AND APPLICATION N86-18338 } \\
& \text { OF DYNAMIC SIMULATIONS OF A SUBSONIC WIND } \\
& \text { TUNNEL (NASA) } 16 \mathrm{p} \text { HC AO2/MF AO1 CSCL } 14 \mathrm{~B} \\
& \text { G3/14 } \quad \text { Unclas }
\end{aligned}
$$

Prepared for the

14th Aerodynamic Testing Conference

sponsored by the American Institute of Aeronautics and Astronautics

West Palm Beach, Florida, March 5-7, 1986

\section{N/SN}


DEVELOPMENT AND APPLICATION OF DYNAMIC SIMULATIONS OF A SUBSONIC WIND TUNNEL

John R. Szuch, Gary L. Cole, Robert C. Seidel, and Dale J. Arpasi

National Aeronautics and Space Administration

Lewis Research Center

Cleveland, Ohio 44135

\section{Abstract}

Efforts are currently underway at NASA Lewis to improve and expand ground test facilities and to develop supporting technologies to meet anticipated aeropropulsion research needs. Many of these efforts have been focused on a proposed rehabilitation of the Altitude Wind Tunnel (AWT). In order to insure a technically sound design, an AWT modeling program (both analytical and physical) was initiated to provide input to the AWT final design process. This paper describes the approach taken to develop analytical, dynamic computer simulations of the AWT, and the use of these simulations as test-beds for (1) predicting the dynamic response characteristics of the AWT and (2) evaluating proposed AWT control concepts. Plans for developing a portable, real-time simulator for the AWT facility are also described.

\section{Introduction}

The National Aeronautics and Space Administration, through the work conducted by the Lewis Research Center in Cleveland, Ohio, is committed to the continued advancement of aircraft propulsion technology. New technologies, such as convertible engine cycles, high speed propellers, composite materials, ice protection, and advanced controls and avionics, are being developed to satisfy more demanding mission requirements. In addition to having improved performance, future aircraft will also require a higher degree of propulsion-airframe integration when compared with current aircraft.

While the U.S. has excellent test facilities, the development of new aircraft technologies will require new and different test capabilities.1,2 As shown in Fig. 1, ground testing of these new systems will require concurrent simulation of pressure and temperature, the ability to test large or full scale hardware, air speeds approaching Mach 1.0, wind tunnel configurations with good flow quality and anechoic properties, the ability to operate/simulate propulsion systems, and the ability to simulate icing and heavy rain.

Efforts are currently underway at NASA Lewis to improve and expand ground test facilities to meet these anticipated aeropropulsion research needs. Many of these efforts have been focused on a proposed rehabilitation of the Altitude Wind Tunnel (AWT).

The AWT was first brought on-line in 1944 and was utilized for aeropropulsion research until 1958 when it was converted into a series of altitude test chambers for space research. A photograph of AWT in its original (and current) configuration is shown in Fig. 2. In the proposed rehabilitation, the Mach number would be extended from 0.6 to $0.9+$ and the altitude pressure from 30000 to $55000 \mathrm{ft}$ while maintaining a $-40{ }^{\circ} \mathrm{F}$ capability. The new facility would also provide an adverse weather test environment (icing, freezing rain, heavy rain, and snow), and would be designed to permit acoustical measurements to be made in the test section.

Because of the extensiveness of the proposed AWT rehabilitation and the significant technical challenges that it would entail, a modeling program (both analytical and physical) was undertaken to insure the technical soundness of the AWT design concept. A companion paper ${ }^{3}$ describes the steady-state analytical and physical modeling activities.

This paper describes the dynamic (i.e., system) analysis activities that were undertaken as part of the AWT effort. The formulation of mathematical models and computer simulations of the AWT is discussed. The approach taken to assess proposed AWT control designs is discussed and examples of transient results from analysis of the AWT control systems are presented. Finally, the paper describes a parallel-processor concept for a real-time facility simulator and the status of parallel-processor technology efforts at Lewis. The systems analysis approach that was used for the AWT should be considered generic and could be applied to any aerospace system or facility development.

\section{Facility Configuration}

A schematic of the proposed AWT facility is shown in Fig. 3 . The $20 \mathrm{ft}$ diameter test section would be slotted and surrounded by a plenum. A plenum evacuation system (PES) would provide for high quality test section airflow with large blockage test articles. Downstream of the test section would be a high-speed diffuser and engine exhaust removal scoop that would permit the testing of fuel-burning engines in the test section. In addition to the exhaust scoop, a provision for nonpropulsion exhaust from the tunnel would be provided downstream of the first corner. The main tunnel fan would be downstream of the second corner with the fan drive shaft extending through that corner. A freon-air heat exchanger would be located in the back-leg to remove the heat addition from the fan. At the exit of the fan, PES reentry air and makeup air (for altitude control) would be injected into the tunnel. Located upstream of the test section, flow conditioners (honeycomb and screens) would provide good flow quality in the test section and a removable spray bar system would generate the icing cloud when the tunnel is being used for icing research.

\section{Systems Analysis Approach}

A systems analys is approach was adopted that effectively utilized the Lewis Research Center's experience in internal fluid mechanics, math modeling, computer simulation, and controls. Lewis has been involved in both experimental and analytical aspects of air-breathing propulsion sys- 
tems for many years. In the case of controls, Lewis engineers have developed many computer simulations of propulsion systems. ${ }^{4,5}$ These simulations have been used to predict the dynamic response of propulsion systems and to design and test algorithms and software for advanced propulsion controls. Real-time simulations have been interfaced directly with actual control system hardware to provide realistic test-beds for yali-
dating controls prior to full-scale tests. 6,7

Because of this extensive background, it was decided to apply the proven math modeling, simulation, and computer technologies to the design and analytical evaluation of wind tunnel controls.

A three-pronged approach to the wind tunnel system analysis was planned as shown in Fig. 4. One of the major efforts would be the development of dynamic, mathematical models of the tunnel components and subsystems. The simulations could be used separately and/or combined to form an overall system simulation. The simulations would be used to predict and analyze the transient behavior of the tunnel and for evaluating proposed control system concepts and algorithms prior to the final design and construction.

The system analysis also would involve an assessment of the tunnel control systems using, first, the separate subsystem simulations and, then, the integrated system simulation. The assessment would be aimed at identifying, prior to final design, any critical control system problems that might prevent the tunnel from meeting the desired response and steadiness goals. The simulations could be used to predict the achievable transient performance and to evaluate various control strategies and algorithms under normal and abnormal operating conditions.

Once construction of a facility is completed, the physical subsystems (i.e., processes and controls) must be tested. Prior to the start of this testing, some form of realistic operator training and verification of control system (i.e., hardware and software) functions is needed. A dedicated, real-time, computer simulation of the tunnel processes would reduce the time, cost, and risk associated with accomplishing these tasks. A parallel-processor concept for such a simulator has been developed at Lewis.8,9 The planned system analysis would include the buildup of a prototype parallel-processor simulator for the wind tunnel application.

\section{AWT Modeling Background}

Initial math modeling of the AWT was based on work performed by Sverdrup Technologies Inc. during the Preliminary Engineering Report (PER) phase of the rehabilitation project. The contractor initiated the math modeling and simulation of the AWT system to aid in establishing cost estimates for the rehabilitation. However, only a lumpedparameter model of the circuit and a first-cut at a model of the in-tunnel heat exchanger and refrigeration subsystem were developed. After reviewing the PER work, a plan was formulated at Lewis to complete the modeling and simulation of the AWT and to use the simulation to guide the detailed design of the AWT controls.
The plan actually called for developing multiple simulations. Stand-alone simulations of the individual subsystems would be developed and used to gain early insight into process dynamics and possible control problems. The subsystem simulations would then be combined to form a fairly complete system simulation, that would run on the IBM 3033 mainframe, providing a long-term simulation capability that would serve the AWT throughout the design, construction, and checkout phases of the project. Also, to provide a nearer-term "workhorse" for conducting the controls studies, a simplified version of the system simulation would be developed. The Lewis hybrid computer system would be used since it provides rapid (faster-than-real-time) response and a high degree of interaction between the controls engineer and the simulation. As experimental data would become available from the physical models, all simulations would be validated and refined so as to increase confidence in the resulting control designs.

\section{Simulation Development}

The following sections describe the approach used to formulate and implement the AWT dynamic models and simulations. A block diagram of the overall tunnel model and proposed control architecture is shown in Fig. 5. The AWT system model consisted of the following subsystem models: tunnel circuit and fan, refrigeration (including the in-tunnel heat exchanger), fan drive, makeup air, exhaust, and plenum evacuation. Each subsystem model included a representation of the associated control system components.

\section{Subsystem Models}

In formulating mathematical models of the AWT subsystems, a primary consideration was the planned use of the simulations for studies of control system dynamics. The fact that the subsystem simulations would have to be combined to form a larger, overall system simulation and that control studies would require the running of long transients ( 1 to 10 min typical), dictated that the models be as computationally simple as possible yet produce reasonably accurate steady-state and dynamic solutions over the entire AWT operating range. To accomplish this, a one-dimensional, lumped-parameter, finite-difference approach was used to obtain sets of ordinary differential equations whose dynamic response characteristics approximated those that would be obtained from the more general partial differential (wave) equations that describe flow in ducts and pipes. Wherever practical, subsystems were initially represented by overall transfer functions. This provided timely information regarding subsystem response requirements. Then details could be added to the subsystem models (e.g., piping losses, valve characteristics, actuator dynamics, compressor maps) to permit simulation studies to be performed at the component level. The following sections describe the models for two of the subsystems the circuit and fan subsystem and the makeup air subsystem.

Circuit and fan. For modeling purposes, the AWT circuit (not including the fan) was divided into five "lumps". Figure 6 illustrates how the lumps were arranged. For each lump, dynamic forms of the mass, energy, and momentum conservation 
equations were written. The conservation equations allowed for the addition/removal of air from selected lumps (e.g., makeup and PES air into lump 1) and for the addition/removal of heat (e.g., heat removal from lump 2).

The fan was represented by a volumeless lump. A bivariate map was used to compute the fan corrected airflow for specified values of fan total pressure ratio and fan corrected speed. The fan upstream and downstream conditions were supplied by the adjacent circuit lumps. The adiabatic efficiency of the fan was assumed to be constant. The circuit model had 18 state variables (i.e., static densities, internal energies, and mass flowrates).

Makeup Air. A block diagram representation of the makeup air subsystem model, which is typical of the AWT subsystems, is given in Fig. 7. The AWT inakeup air system would deliver, upon command, the correct amount of air from the Lewis Propulsion System Laboratory (PSL) compressors to maintain a desired facility altitude (i.e., pressure) and to compensate for the loss of air during propulsion testing. The makeup air system would have to be capable of supplying up to 400 pps of 150 psig dry air at $-20^{\circ} \mathrm{F}$ to the tunnel. In the model, the PSL compressors were represented by a regulated pressure source. The makeup air piping was broken into four lumps, each approximately $300 \mathrm{ft}$ in length. An "ideal" air cooler was assumed between the third and fourth lumps. Upstream of the cooler, the air was assumed to be at a fixed temperature. Downstream of the cooler, the air was assumed to be at the tunnel temperature. A control valve was assumed to be located downstream of the fourth lump. The valve flow was injected into a volume, representing a torus downstream of the fan. The torus would feed eight injection nozzles with the nozzle back pressures determined by the tunnel conditions. In the circuit model, only the mass addition from the makeup air nozzle was considered (no energy addition). The makeup air control valve actuator and servo were modeled as a second order lag. In the model, the makeup air flow command was assumed to be computed by an outer-loop, proportional-plus-integral (PPI) controller, based on a commanded tunnel pressure. Excluding the pressure and flow controllers, the makeup air subsystem model had nine state variables (pressures and mass flowrates).

\section{Digital Simulation}

The subsystem models were coded in Fortran and run separately on the IBM 3033. To solve the nonlinear differential equations, a second-order Runge Kutta integration algorithm was used with a time step of $5 \mathrm{msec}$. A main Fortran program was structured to allow convenient integration of subsystem models and also to permit the use of analysis routines that were previously developed at Lewis. These analysis routines facilitate the generation of linear system matrices, eigenvalues, and frequency response plots.

Because of the importance of the circuit model dynamics in any tunnel control design or assessment, an attempt was made to validate the circuit model. The Fortran simulation was first run to steady-state conditions at selected operating points. Comparison of steady-state values of pressures, temperatures, and flows with values obtained from Sverdrup's steady-state performance code generally showed errors to be less than 3 percent. These results were deemed satisfactory for the planned controls assessment.

Having established the steady-state validity of the circuit model, the analysis routines were used to generate selected step and frequency responses. For example, Fig. 8 shows the simulated response of test section mach number to sinusoidal changes in fan speed at the $32000 \mathrm{ft}$, Mach 0.8 condition. To determine if the simulated circuit response predictions were reasonable, corresponding response data were obtained from a linear, distributed circuit model that had been developed for the same condition. Figure 8 shows a comparison of the lumped-parameter and distributed model response amplitudes. The amplitude results indicated that the five-lump nonlinear circuit model provided a reasonable approximation of the linear distributed model and that the resonant characteristics of the lumpedparameter model would lead to "safe" control designs. The phase angle results (i.e., 180 degree crossover frequencies), although not shown, were also in good agreement.

While the objective of the digital simulation development was to create a simulation of the total facility (i.e., integrated subsystems), cutbacks in AWT project funding prevented the completion of the integration task. As a result, the controls assessment was limited to using the separate, digital subsystem simulations and the simplified, hybrid computer version of the AWT system.

\section{Hybrid Simulation}

The hybrid (analog and digital) computer systems at Lewis offered an opportunity to develop, in a timely manner, a dynamic simulation of the overall AWT system, including controls. The computing speed of the analog computers allowed the model equations to be solved faster than real-time (actually 10 times faster). However, the limited complement of analog computer components necessitated some simplification of the math model. The five-lump circuit and fan model, the fan drive model, and the plenum evacuation system model were not modified. However, the heat exchanger and refrigeration model, the makeup air model, and the exhaust model were simplified.

Figure 9 shows a block diagram of the simplified models of the makeup air and exhaust subsystems. The closed-loop responses of the makeup air and exhaust subsystems to changes in flow setpoints (see Fig. 7) were represented by secondorder transfer functions. As shown in Fig. 9, the simplified model assumed that a single PPI controller would be used to maintain a desired total pressure upstream of the test section. Flow-split logic would be used to select the appropriate control action.

\section{Controls Assessment}

The major objective in the operation of experimental test facilities is to achieve the desired performance. The performance criteria are response time, which equates to productivity/cost of operation, and parameter steadiness, which equates to quality of data. The goal of the AWT 
control assessment studies was to insure that the subsystems and their controls would operate, individually and together, to produce the desired test-facility performance.

\section{Control Architecture and Requirements}

Before the control assessment process could begin, an overall control system architecture had to be chosen and performance goals established. The control architecture for the AWT application is shown in Fig. 5. It was hoped that that architecture would allow the subsystems to be dynamically decoupled. This would permit meaningful subsystem control designs and analyses to be carried on separately (a simplification) and in parallel (a time savings).

Once a control architecture was chosen, performance goals were established. These goals were established based on the results of studies that were conducted during the PER phase. A simple model (similar to the hybrid model) was used at that time to determine if typical experimental test scenarios could be accomplished.

\section{Assessment Approach}

Once the control architecture and performance goals were established, the controls assessment could begin. The controls assessment approach is outlined in Fig. 10. To the extent possible, the detailed mathematical models of the individual subsystems were utilized with mathematical models of the subsystem controls (see Fig. 5) added. The following models were developed in parallel: pressure altitude system (composed of the makeup and exhaust air systems), temperature altitude system (composed of the in-tunnel heat exchanger and other refrigeration system components), Mach number system (composed of the fan drive), and the PES. An example of one detailed model is the makeup air system that was described in an earlier section and is shown schematically in Fig. 7.

Once the detailed subsystem models were available, assessments of the individual controls (i.e., design and evaluation) were initiated. The individual subsystem studies were expected to produce the following types of information: (1) whether or not the specified closed-loop performance goals could be achieved, (2) whether or not the required control element response and rate limit specifications would be within the state of the art, (3) whether control gain scheduling would be required to achieve a uniform response over the range of expected operating conditions, and (4) identification of subsystem failure modes and effects that would adversely impact the subsystem or facility. As individual subsystem studies were completed, the subsystem models were to be integrated to form a detailed systems model.

The detailed systems model would then be used to (1) confirm that the overall plant (AWT) performance goals (response/steadiness) could be achieved, (2) evaluate dynamic interactions between subsystems resulting from outer-loop controller set-point changes, (3) determine actuator and sensor specifications, such as the amount of hysteresis and deadband required to meet steadiness goals, (4) investigate digital controller requirements, such as sampling rates, (5) adjust outer-loop controller gains and/or set-point schedules to provide uniform response characteristics over the operating range of the facility, and (6) conduct additional failure modes and effects analyses. All this information would provide valuable knowledge and a data base for use in the facility design effort.

\section{Assessment Results}

The AWT individual subsystem assessment process was carried out as described above. Because of cutbacks in AWT funding, these studies were concentrated on subsystem performance at the tunnel design operating condition of Mach 0.8 and $32000 \mathrm{ft}$ altitude. Little investigation was done at off-design conditions. Some results and general conclusions for these studies will be discussed in a subsequent paragraph. The hybrid systems simulation mentioned earlier, incorporating simplified subsystems models (block diagram of Fig. 10), was used only for a cursory investigation of set-point interactions. The main conclusion from these studies was that the chosen control architecture should provide for stable tunnel operation.

Results from the subsystem studies indicated that, for the most part, the subsystem performance goals were achievable with state-of-the-art actuator dynamics at the tunnel design operating condition. An example of results obtained with the makeup air subsystem model is given in Fig. 11 . The open-loop response of makeup airflow into the tunnel to a step change in control valve position is shown in Fig. 11(a). The system response was found to be approximately equivalent to that of a first order lag with a time constant of $1.36 \mathrm{sec}$. The first order lag approximation was used to determine proportional-plus-integral (PPI) controller gains that would, theoretically, produce the desired closed-loop makeup airflow response. These gains were then implemented in the nonlinear model and the resultant closed-loop transient response of airflow to a step change in flow set point was investigated. The nonlinear model results for a one percent step change is shown in Fig. 11(b). The actual response corresponded to a second-order natural frequency of $7 \mathrm{rad} / \mathrm{sec}$ (somewhat slower than the response goal of $10 \mathrm{rad} / \mathrm{sec}$ ).

Based on limited studies of the subsystems at off-design operating conditions, it appeared that many of the subsystems would require controller gain scheduling to achieve uniform subsystem responses over the range of tunnel operating conditions.

\section{Real-Time Simulator}

As an outgrowth of parallel-processor technology work at Lewis, an experimental real-time multiprocessor simulator (RTMPS) system became operational in CY84. Because of the potential cost- and time-saving benefits of having a realtime simulator in the AWT facility, system analysis efforts were directed at (1) developing a representative benchmark simulation of the AWT circuit and fan model that would run on the RTMPS and (2) conducting a study to define specific facility applications of a simulator and establish a methodology for determining simulator design requirements. 
Figure 12 shows a photograph of the experimental RTMPS. The basic computational elements in the RTMPS are single-board microcomputers. The microcomputers are arranged as three dualprocessor channels. If there is inherent parallelism in a set of simulation equations, those equations may be broken up and solved concurrently on the six processors. The processors, within a channel, communicate through a shared memory. The RTMPS uses a dual-bus architecture for communication between channels. More detailed information on the RTMPS hardware can be found in Ref. 9.

An interactive, real-time multiprocessor operating system, RTMPOS has also been developed for the RTMPS. 10 The operating system provides the user with engineering-level, run-time operations such as loading and modifying of programs, simulator mode control, data nandling, and monitoring of results.

A high-level, structured programming language, RTMPL has been developed for the RTMPS. 11 The language and its translator utility act as an assembly language programmer, translating the high-level simulation description into timeefficient assembly language code for the microprocessors. The language is macro-based and several often-used simulation functions (e.g., integration, table lookups) have been preprogrammed for convenient use in RTMPL programs.

The five-lump model of the AWT circuit was coded in RTMPL for solution on a single RTMPOS processor. Timing tests were performed. A single pass through the circuit equations took $7.0 \mathrm{msec}$. The same equations were later executed in $1.9 \mathrm{msec}$ using a higher-performance computer board. These results, together with extrapolations of multiprocessor results for an earlier turboshaft engine simulation, indicated that the proposed AWT simulator should be able produce real-time response.

Given that available simulator technology can produce real-time representations of the facility processes, there are a number of facility operational activities that could benefit from having a simulator as part of the facility. An applications and requirements study 12 was conducted as part of the system analysis effort. The study identified several applications along with their primary impact (i.e., cost, safety, or reliability). That study also identified a general facility/controls/simulator configuration and 16 configuration options that would serve those applications.

\section{Concluding Remarks}

This paper described a systematic approach to developing and applying computer simulations to support the development of a large facility. The approach involves the formulation of mathematical models and stand-alone simulations of the major facility subsystems. The use of separate subsystem simulations provides for an early determination of subsystem dynamic behavior and development of "first-cut" subsystem control designs. Integration of the subsystem simulations leads to a modular system simulation that can be used to evaluate subsystem interactions and "tune" the controls to satisfy desired performance goals. Because of the long run-times associated with control studies, it is desirable to develop a simplified, real-time (or faster-than-real-time) simulation of the overall system. The simplified simulation can be used to provide timely evaluations of control architectures, algorithms, and gains with the detailed system simulation providing final verification. Experience gained in the AWT project indicates that the system analysis approach can lead to timely development of an arsenal of powerful, well-understood, and welldocumented simulations that can aid in the understanding, design, and operation of a complex dynamic system, such as a wind tunnel.

\section{References}

1. Blaha, B.J., and Shaw, R.J., "The NASA Altitude Wind Tunnel: Its Role in Advanced Icing Research and Development," AIAA Paper 85-0090, Jan. 1985.

2. Miller, B.A., and Chamberlin, R., "Altitude Wind Tunnel (AWT) A Unique Facility for Propulsion System and Adverse Weather Testing," AIAA Paper 85-0314, Jan. 1985.

3. Ciepluch, C.C., "Progress in the Lewis Research Center Altitude Wind Tunnel Modeling Program," Paper proposed for presentation at AIAA 14th Aerodynamic Testing Conference, West Palm Beach, FL, Mar. 5-7, 1986.

4. Szuch, J.R., Seldner, K., and Cwynar, D.S., "Development and Verification of a Real-Time Hybrid Computer Simulation of the F100-PW100(3) Turbofan Engine," NASA TP-1034, 1977.

5. Daniele, C.J., Krosel, S.M., Szuch, J.R., and Westerkamp, E.J., "Digital Computer Program for Generating Dynamic Turbofan Engine Models (DIGTEM)," NASA TM-83446, 1983.

6. Szuch, J.R., "Application of Real-Time Engine Simulations to the Development of Propulsion System Controls," AIAA Paper 75-1176, Sept. 1975.

7. Szuch, J.R., Skira, C., and Soeder, J.F., "Evaluation of an F100 Multivariable Control Using a Real-Time Engine Simulation," AIAA Paper 77-835, July 1977.

8. Blech, R.A., and Arpasi, D.J., "An Approach to Real-Time Simulation Using Parallel Processing," Proceedings of the 1981 Summer Computer Simulation Conference, AFIPS Press, Arlington, VA, 1981, pp. 355-360.

9. Blech, R.A., and Arpasi, D.J., "Hardware for a Real-Time Multiprocessor Simulator," Distributed Simulation 1985, P. Reynolds, ed., Society for Computer Simulation, La Jolla, CA, 1985, pp. 43-52.

10. Cole, G.L., "Operating System for a Real-Time Multiprocessor Propulsion System Simulator User's Manual," NASA TP-2426, 1984.

11. Arpasi, D.J., "Real-Time Multiprocessor Programming Language (RTMPL) - User's Manual," NASA TP-2422, 1985.

12. Arpasi, D.J., and Blech, R.A., "Applications and Requirements for Real-Time Simulators in Ground-Test Facilities," Proposed NASA TM. 
- CONCURRENT PRESSURE AND TEMPERATURE SIMULATION OF ALTITUDE

- $\quad$ LARGE SCALE TEST ARTICLES

- FULL SUBSONIC SPEED RANGE

- WIND TUNNEL CONFIGURATIONAERODYNAMICS/ACOUSTICS

- PROPULSION SYSTEM OPERATION/SIMULATION

- ICING, HEAVY RAIN CAPABILITY

NO EXISTING NOR PLANNED FACILITY MEETS THESE NEEDS

Figure 1. - New test facility requirements.

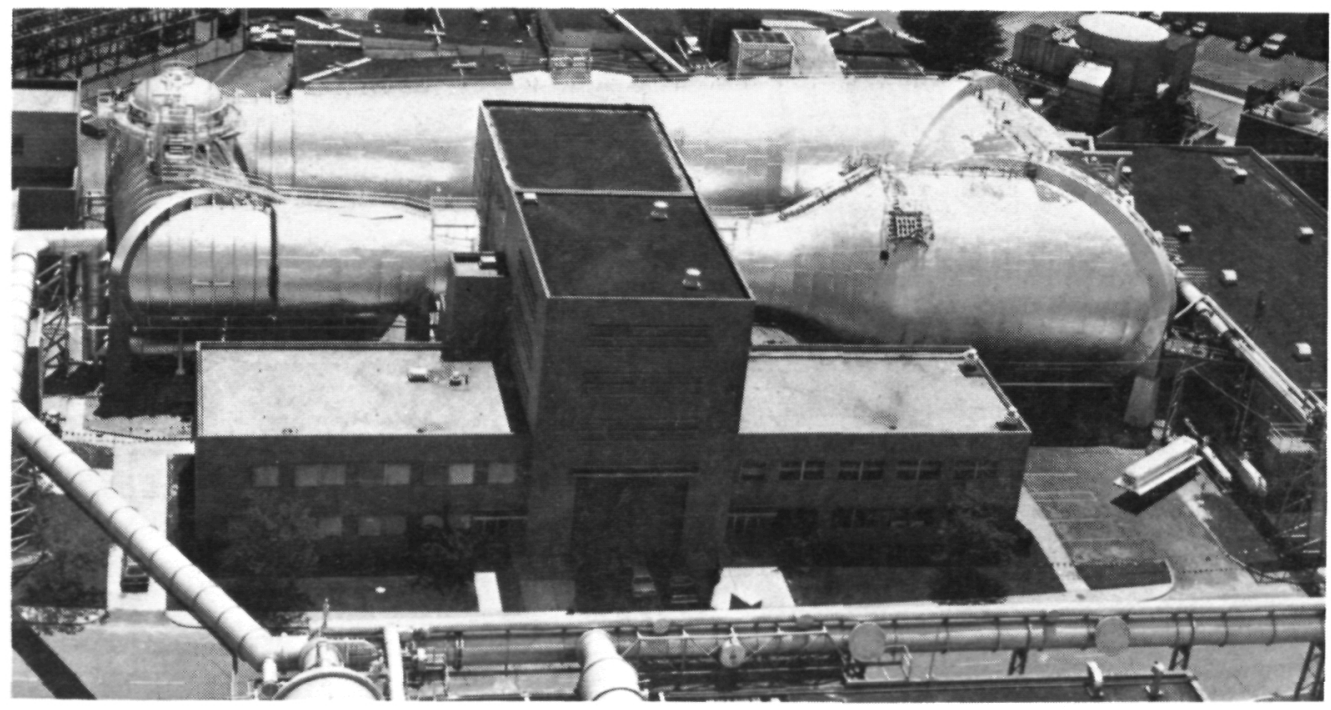

Figure 2. - Altitude wind tunnel would provide new national aeronautical propulsion and icing R\&D capability. 


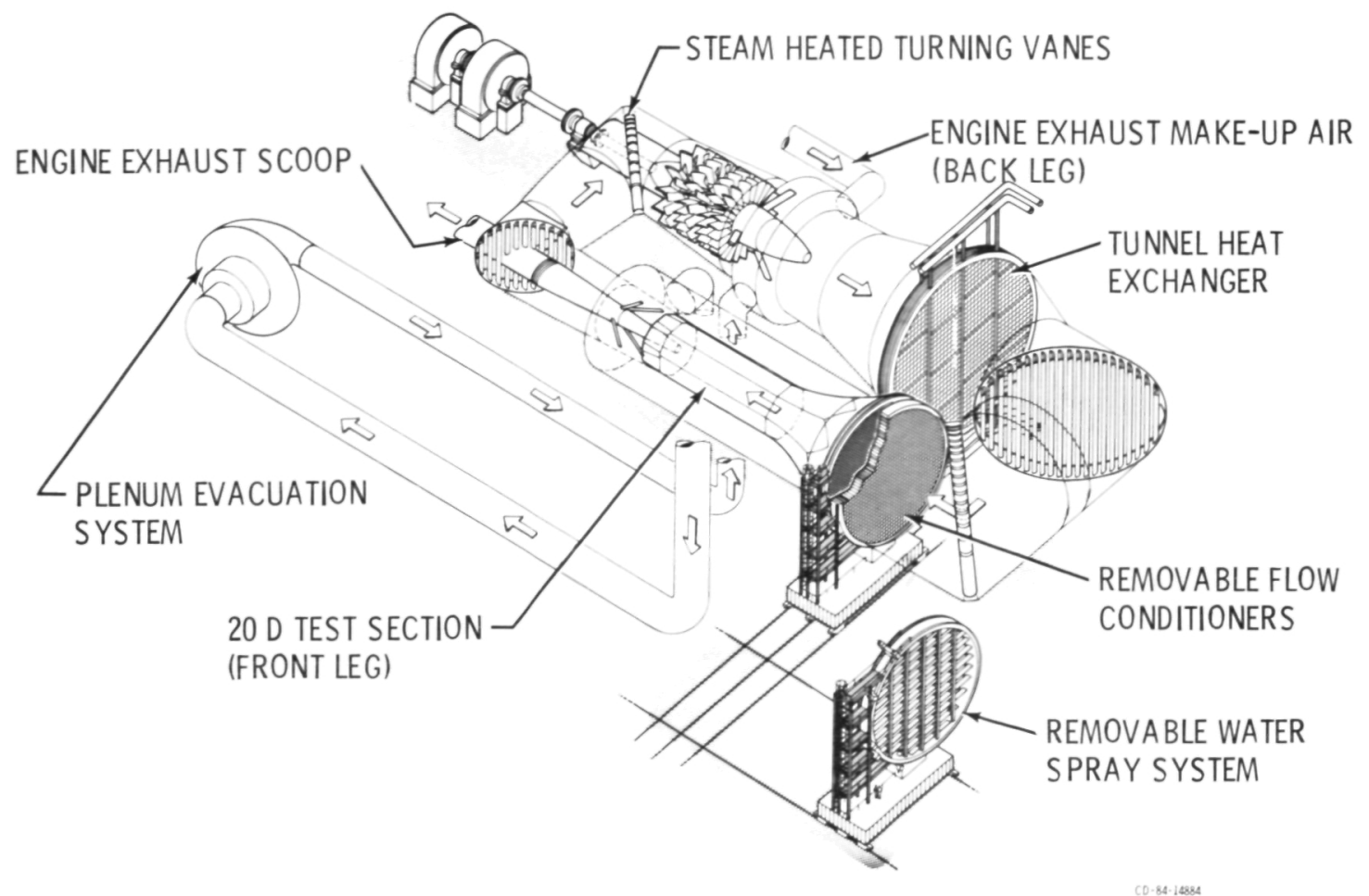

Figure 3. - Altitude wind tunnel special features.

\section{SYSTEMS SIMULATION}

- IBM 370/FORTRAN MOdel OF AWT SYSTEM

- ANALYSIS OF TRANSIENT RESPONSE AND SYSTEM INTERACTIONS

CONTROLS

- real-time simulation using hybRid COMPUTER

- eVALUATION OF PROPOSED CONTROL DESIGNS
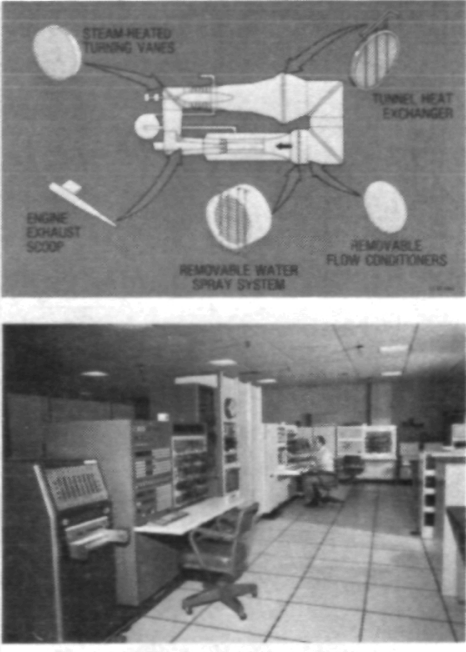

REAL-TIME DIGITAL SIMULATOR

- FACIUTY SIMULATOR FOR PRE-RUN CHECKOUT OF CONTROLS AND OPERATOR TRAINING

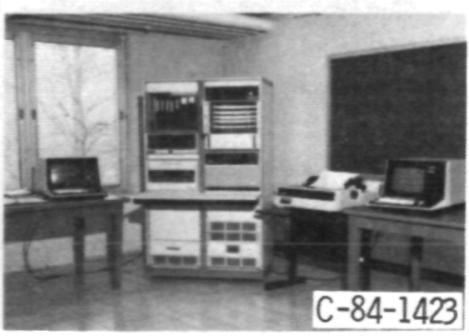

Figure 4. - Systems analysis approach. 

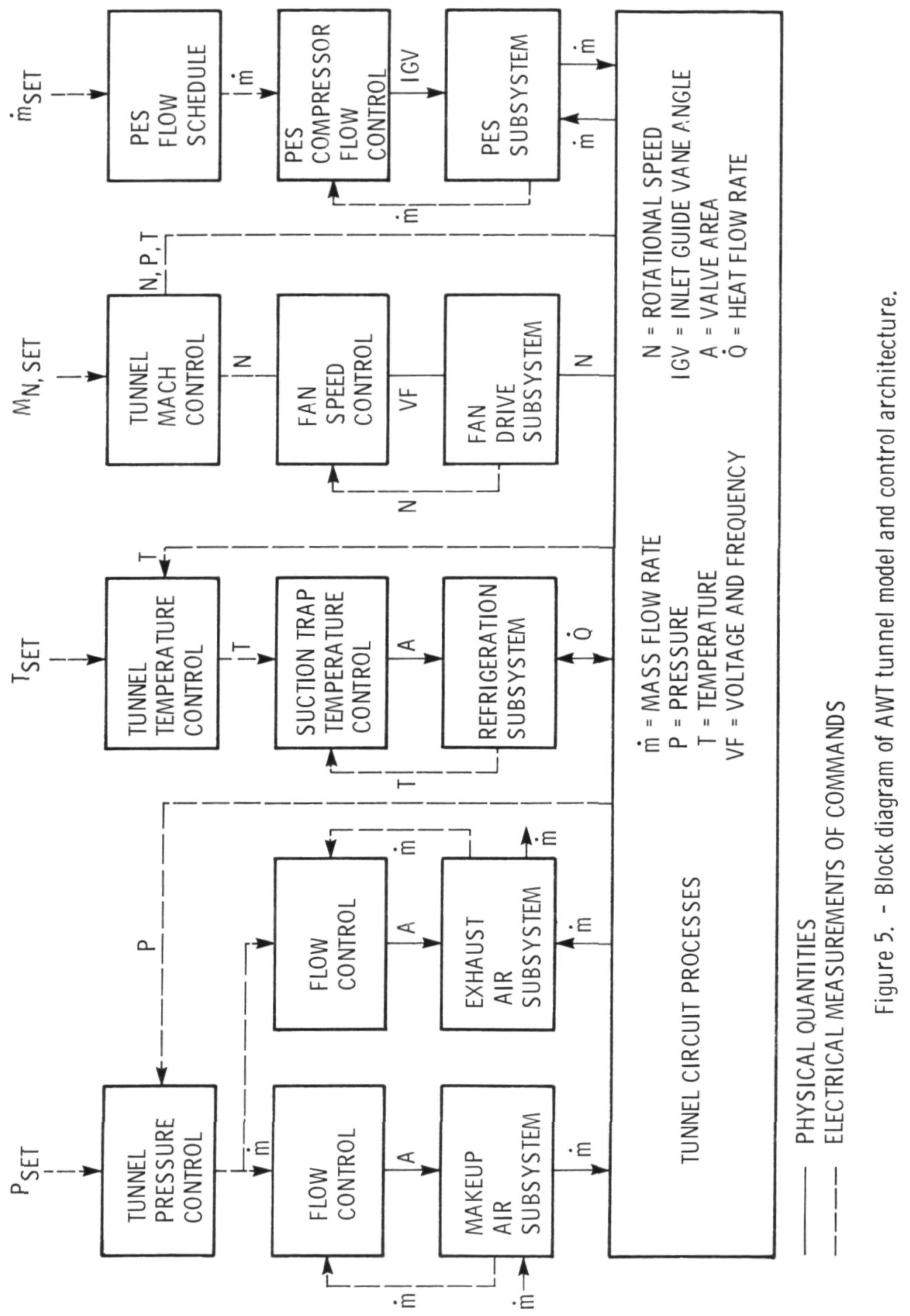


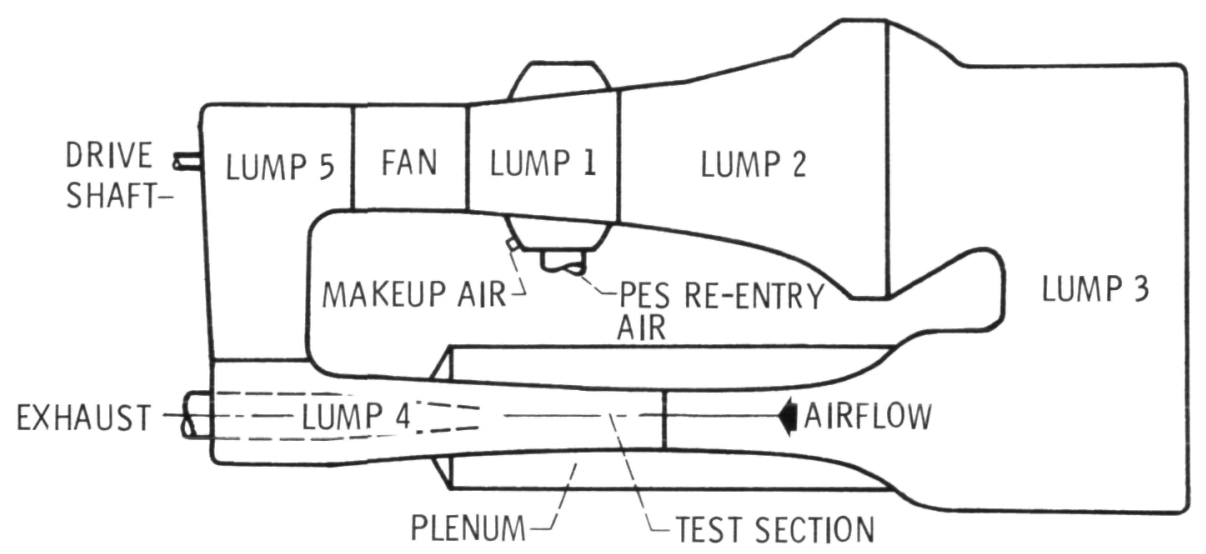

Figure 6. - AWT 5-lump circuit model (17 states). 


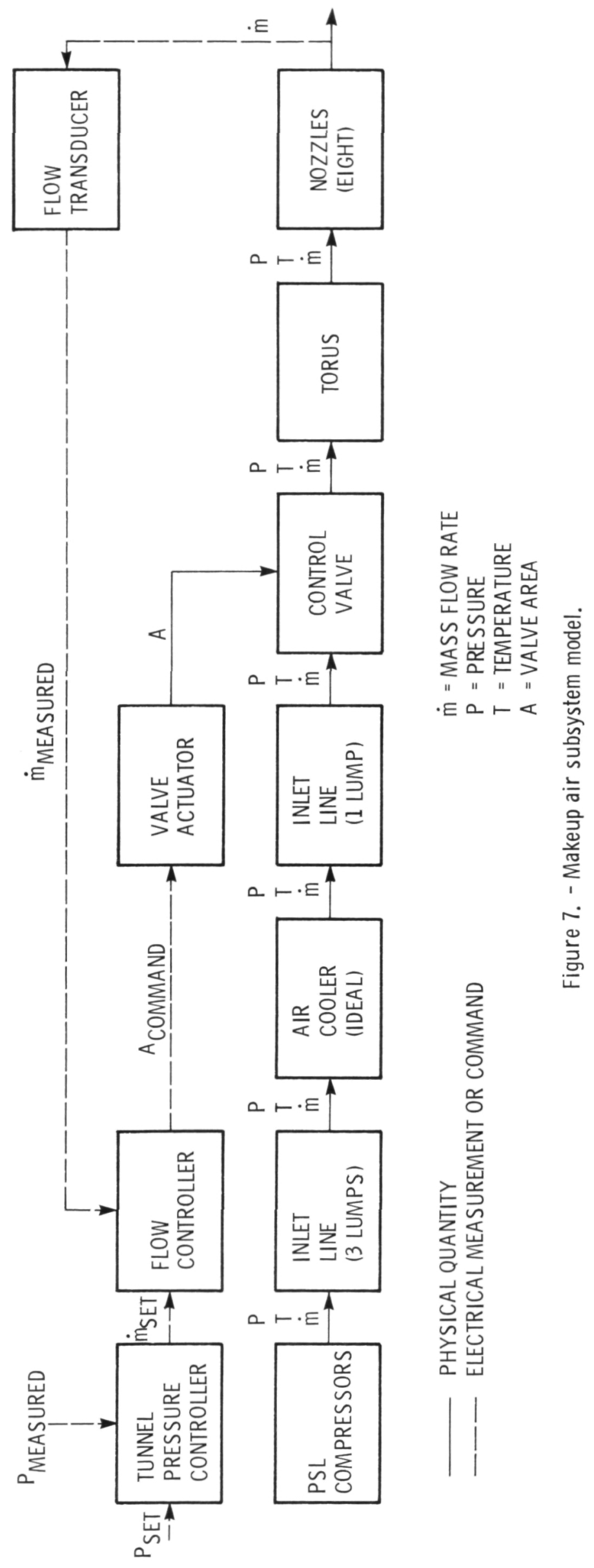




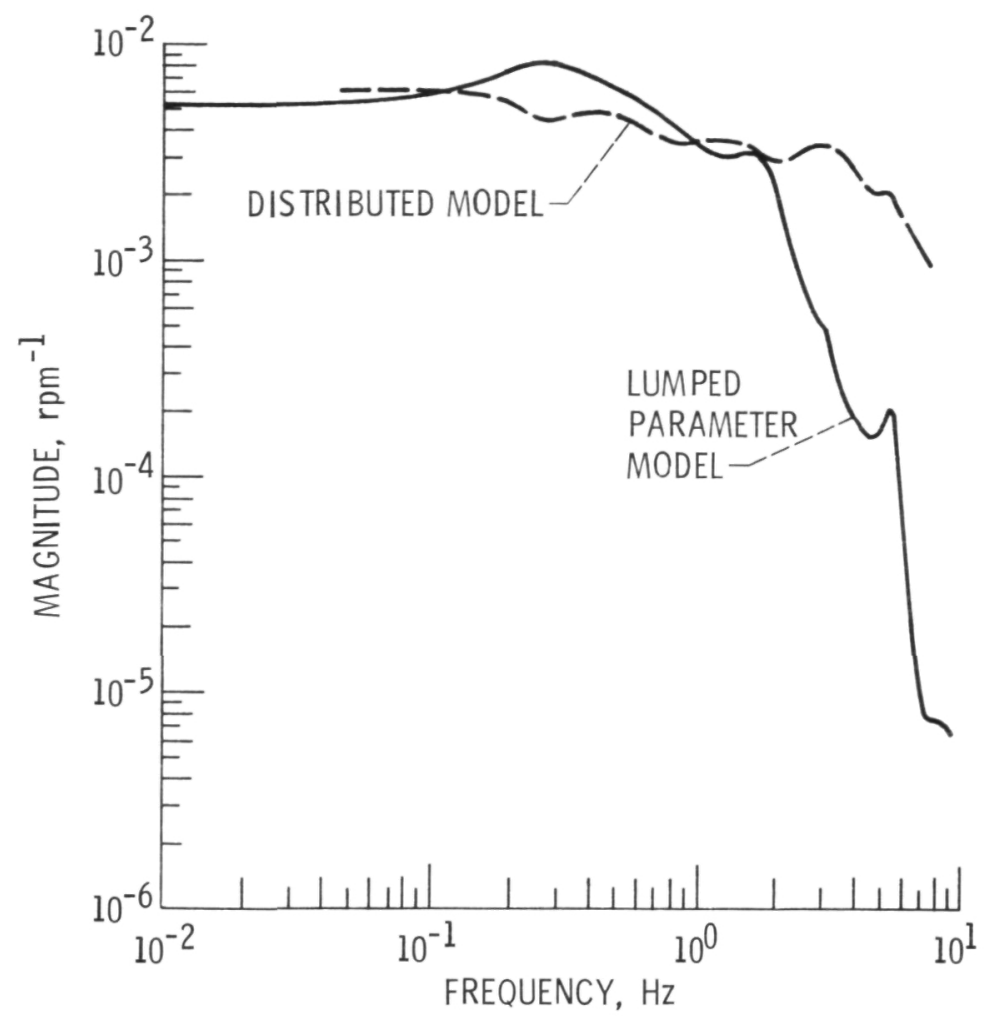

Figure 8. - Comparison of lumped-parameter and distributed circuit models; frequency response of test section Mach number to fan speed.

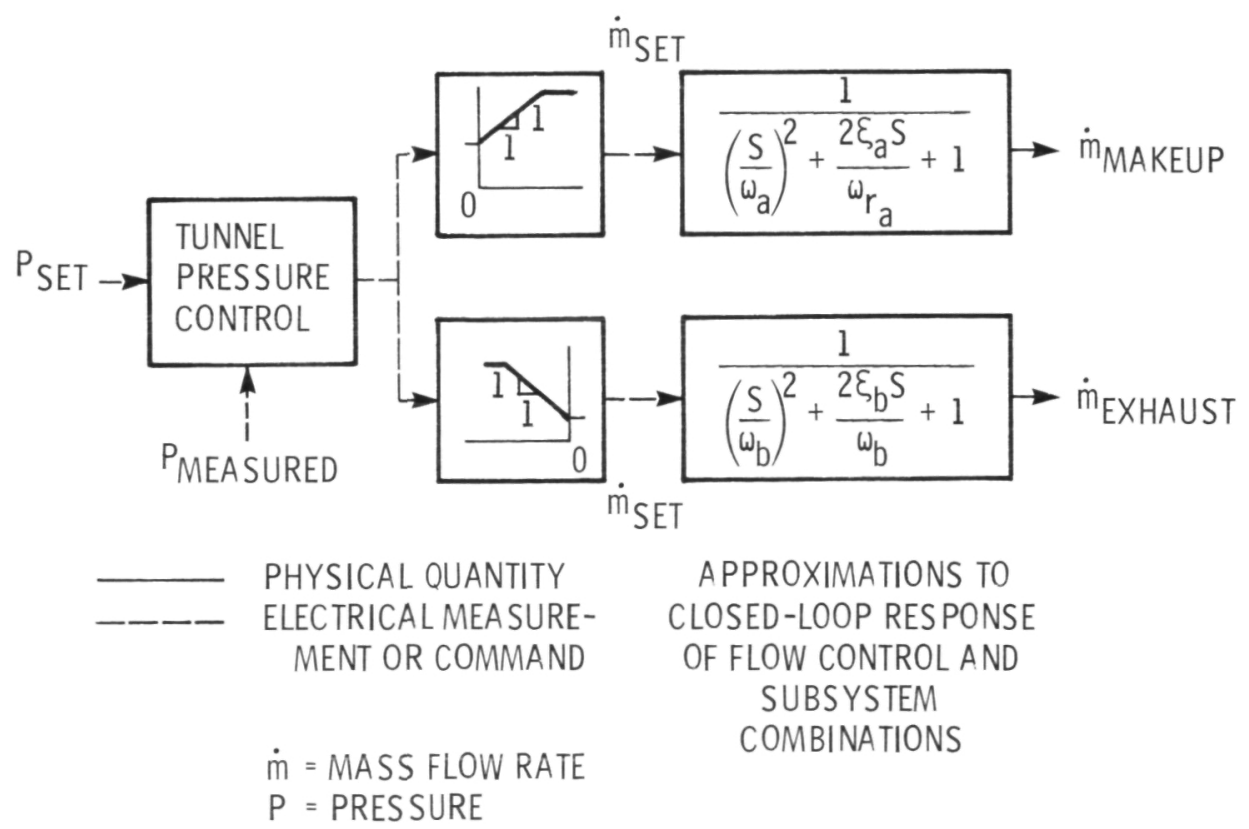

Figure 9. - Simplified makeup air and exhaust subsystem models. 


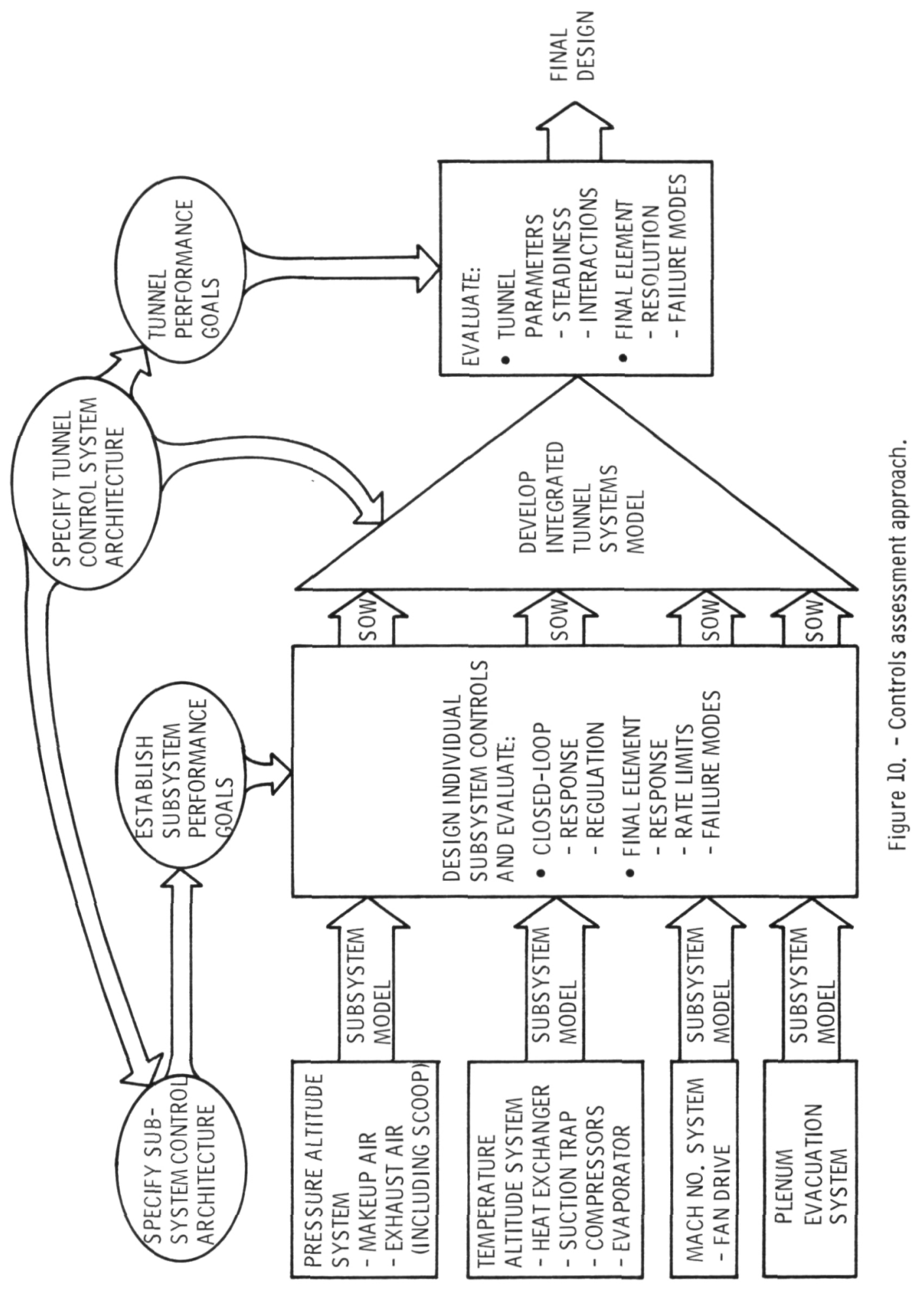




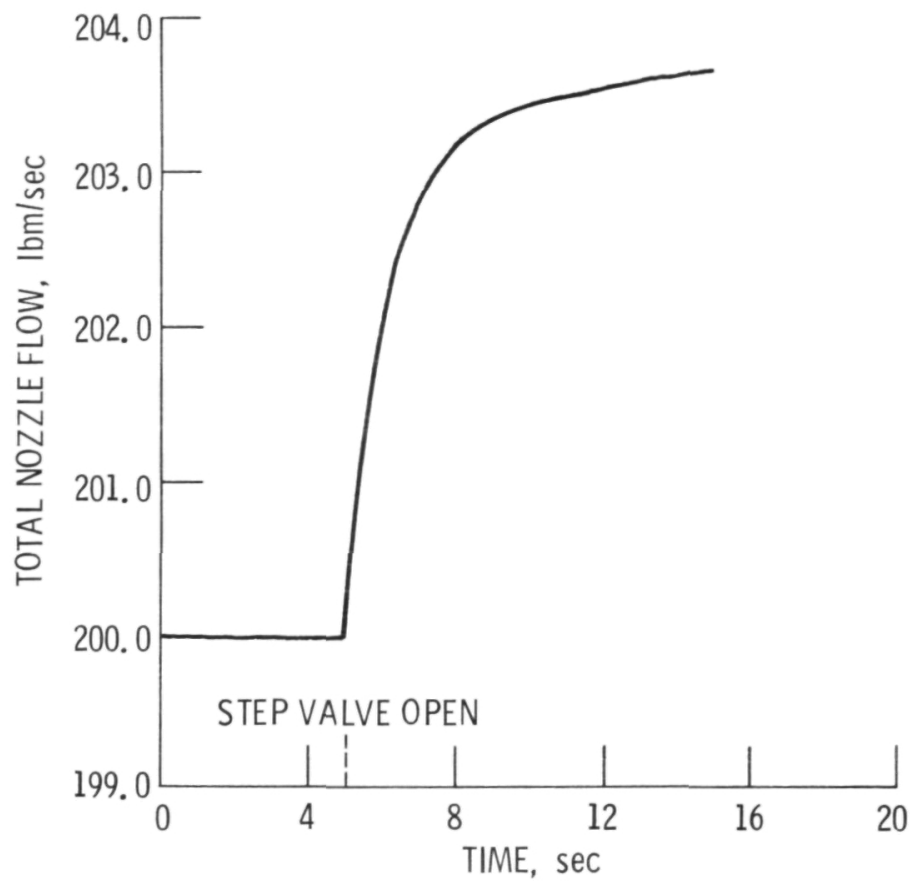

(a) Open-loop response of nozzle flow to 1 percent step change in valve position.

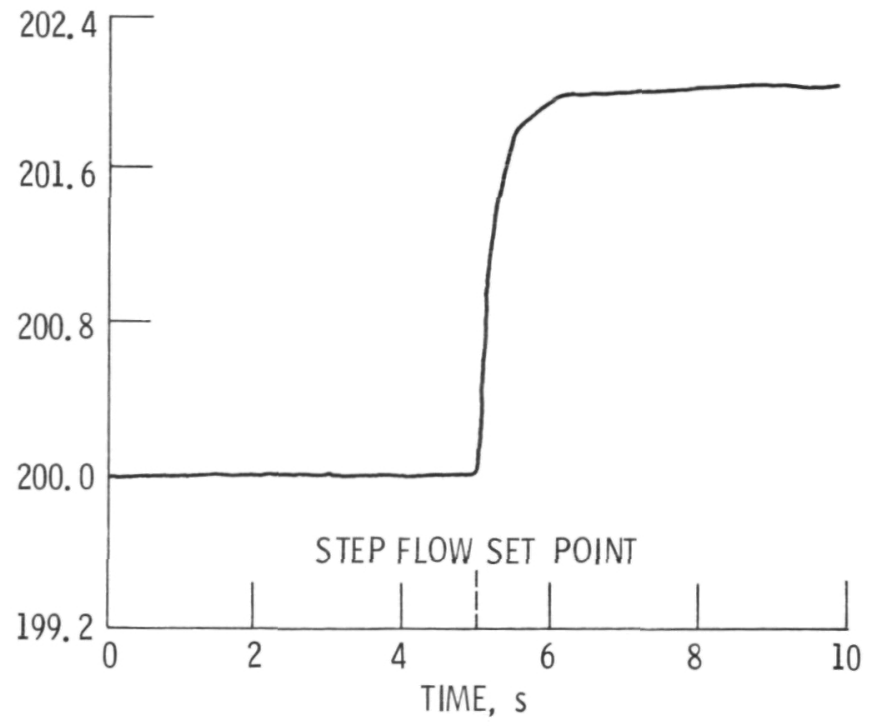

(b) Closed-loop response of nozzle flow to 1 percent step in flow set point.

Figure 11. - Transient response of AWT makeup air subsystem nonlinear model. 


\section{ORIGINAL PAOE IS \\ OF POOR QUALITY}

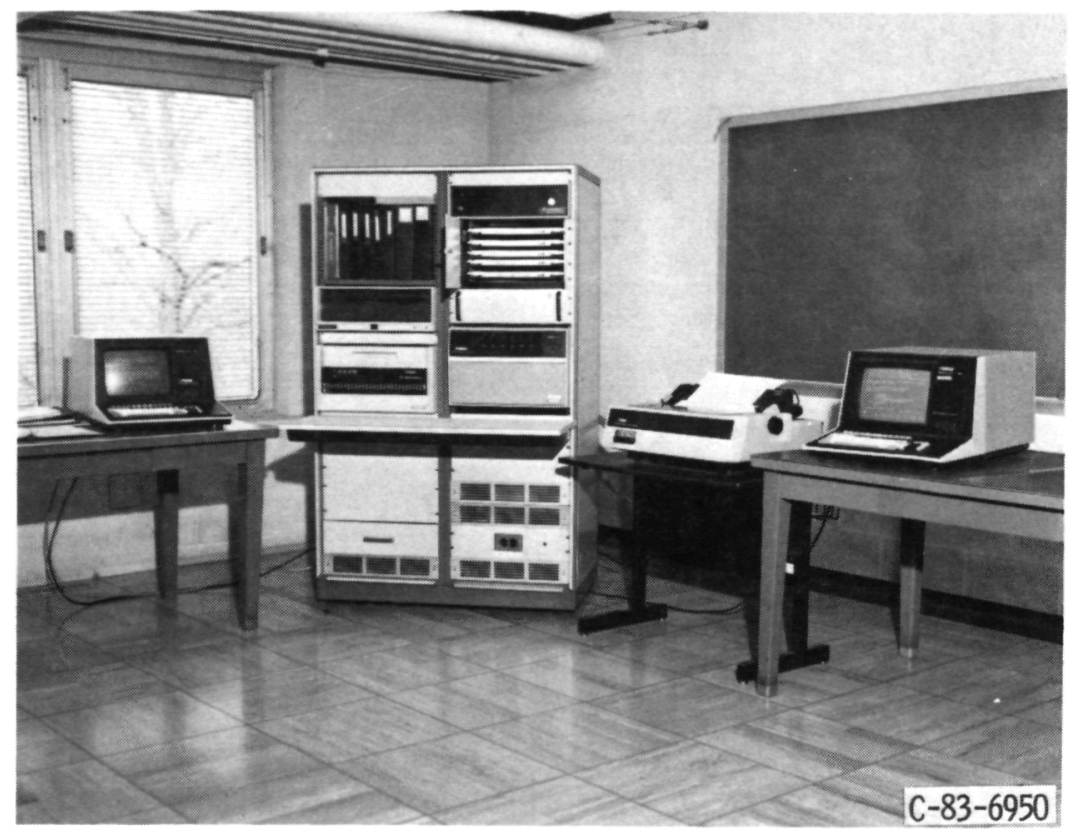

Figure 12. - Real-time multiprocessor simulator. 


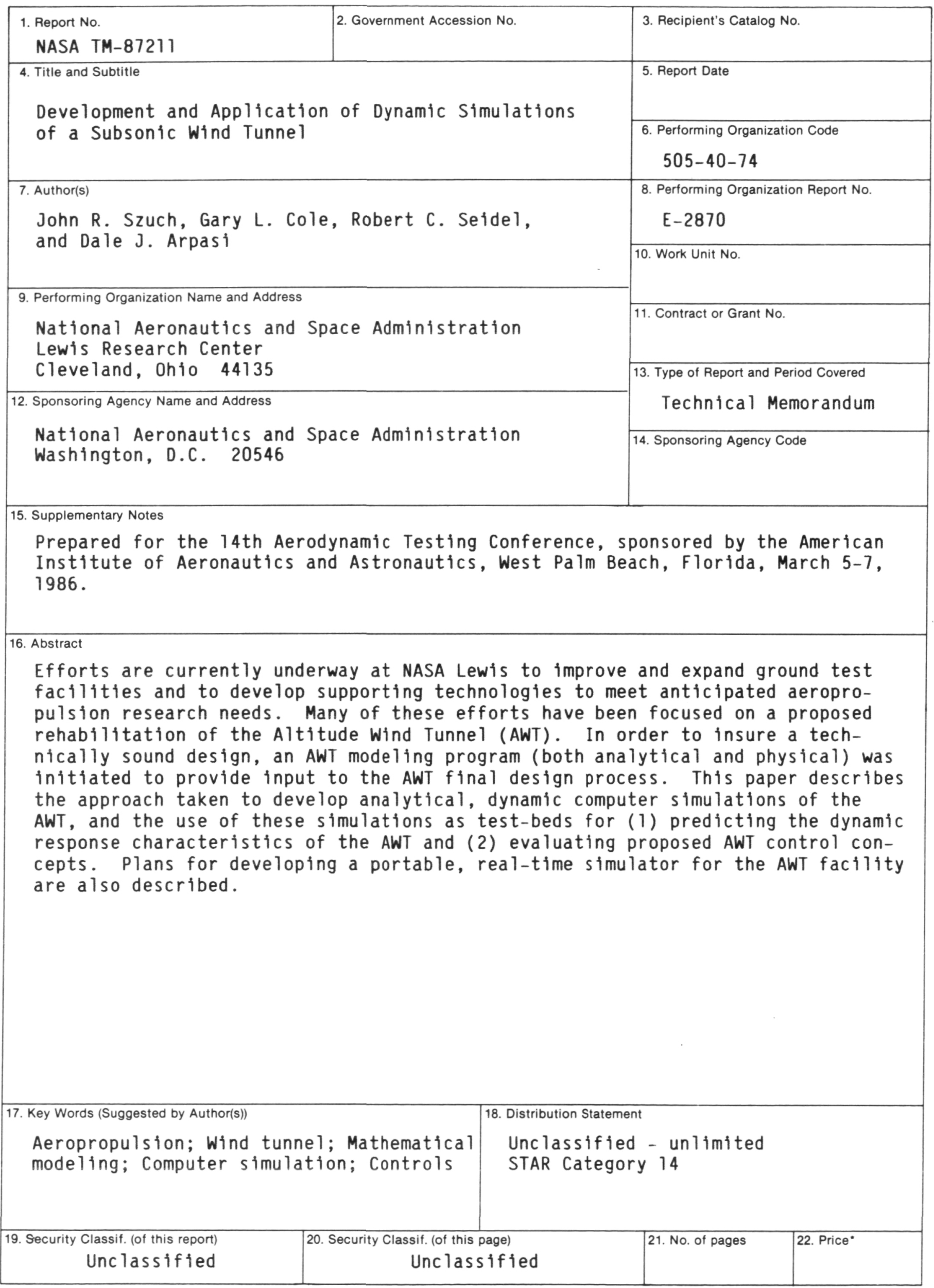

*For sale by the National Technical Information Service, Springfield, Virginia 22161 
National Aeronautics and Space Administration

\section{Lewis Research Center}

Cleveland. Ohio 44135

\section{Otficial Business}

Penalty for Private Use $\$ 300$
SECOND CLASS MAIL

ADDRESS CORRECTION REQUESTED

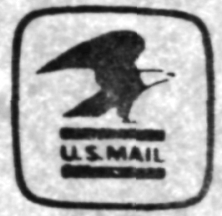

Postage and Fees Paid National Aeronautics and Space Administration NASA-451 